\title{
Mortality of shift and day workers 1956-68
}

\author{
P. J. TAYLOR and S. J. POCOCK \\ TUC Centenary Institute of Occupational Health, London School of Hygiene \\ and Tropical Medicine, London WC1
}

\begin{abstract}
Taylor, P. J., and Pocock, S. J. (1972). Brit. J. industr. Med., 29, 201-207. Mortality of shift and day workers 1956-68. Little research has been reported about the long-term effects of shift work. An investigation is described on 8603 male manual workers from 10 organizations in England and Wales designed to assess the mortality experience of day, shift, and ex-shift workers. Three major types of shift system were involved. All had been employed by the same organization for not less than 10 years and the follow-up period was between 1956 and 1968. Only 22 men could not be completely traced and the cause of death was obtained for all but eight of the 1578 deaths. Man-years at risk for each group were calculated in order to compare observed deaths with those expected from national mortality rates. The overall number of deaths was very close to that expected and no significant excess mortality was found in either the shift or ex-shift groups. Shift workers in some age groups had higher mortality than expected but this was not consistent between either organizations or types of shift work. A study of 14 main causes of death revealed some differences from national experience in both day and shift workers but these can be attributed to regional and occupational differences. To eliminate any occupational factor the mortality of skilled craftsmen and their mates was compared for day and shift work with no evidence of any shift work effect. The results lead to the conclusion that shift work would appear to have no adverse effect upon mortality.
\end{abstract}

Shift work is increasing in industrialized countries. In Great Britain the proportion of employees in manufacturing industry doing shift work rose from $12 \frac{1}{2} \%$ in 1954 to $25 \%$ in 1968 (National Board for Prices and Incomes, 1970). This trend is also apparent in other sectors of the economy and it is estimated that there are now over two million fulltime adult manual workers on shift work and that the numbers are likely to continue to increase.

The effects of shift working on the individual have recently been reviewed (Sergean, 1971), and it is clear that there is still a wide measure of disagreement about its effects on health. There is, for example, abundant evidence that circadian rhythms are disturbed, particularly when night work is involved (Conroy and Mills, 1970), but it is not known whether the dissociation of such rhythms has any long-term effect upon health. One method of investigation is the measurement of mortality, but only one report of such a study has been found (Thiis-Evensen, 1949). This compared the average age at death of 498 day and 212 three-shift workers at three factories of Norsk Hydro between 1917 and 1948. No comparison was made with national figures but Thiis-Evensen concluded that there was no evidence to suggest that shift work adversely affected the expectation of life.

In recent years, the more refined and informative technique of cohort mortality analysis has been developed as a precise tool for the comparative study of mortality (Case and Lea, 1955). It has been used on a number of occasions when it was possible to define a population, recent examples being studies of viscose rayon workers (Tiller, Schilling, and Morris, 1968) and nickel refinery workers (Doll, Morgan, and Speizer, 1970).

This paper describes a mortality study of 8603 male day and shift workers from 10 factories in 
England and Wales between 1956 and 1968, its objective being to assess the influence, if any, of 10 years or more of shift work upon the expectation of life and cause of death.

\section{Methods}

\section{Selection of sample}

While the sample should represent the whole population of shift workers the information does not exist to allow this to be done. On enquiry it transpired that neither trades unions nor friendly societies keep records of shift work among their members. The only possible source of information was from employers with adequate records which had been preserved for a number of years. Data were also required about men who had not done shift work or who had done it only for a relatively short time and thus the co-operation of organizations employing both shift and day workers was sought. With the help of introductions from the Confederation of British Industry and from occupational physicians working full time in industry, 42 organizations offered to assist. Visits and discussions, however, revealed that the majority were unable to provide adequate data, either because details of shift work in the past were not available or because records of men who had left employment in the past had been destroyed. Twelve organizations were finally able to provide the necessary information, and data from 10 of them are included in this paper. Information from the two remaining is still being collected.

For each organization the sample was defined as all men in manual full-time employment on 1 January 1956 , who were born before 1920 and who were continuously employed for at least 10 years between 1946 and 1968 . Men who were subsequently promoted to the staff were included provided that they had first completed 10 years as a manual worker. The restriction to older men was necessary because death rates in the young are so low. The employment record was taken from 1946 because of the disruptive effect of the second world war on patterns of employment and hours of work. The sampling procedure made no reference to shift work.

Two methods were available for organizations to identify men to be included-either a payroll from the beginning of 1956 or the current payroll together with the complete set of 'paid off' records for all who had died, retired or left between 1 January 1956 and 31 December 1968. One organization was able to get complete records only back to 1 January 1958 .

\section{Information obtained}

A form was completed for each man in the sample with the following information: identification, dates of birth and engagement by the firm, a list of all jobs held, and the working hours involved since 1946, each change having the month and year in which it occurred, and finally whether or not he was still employed on 31 December 1968. For those who had died in company service before that date the date of death was required, and for those who had retired or left, the date of leaving and whether alive or dead. As each organization had some type of superannuation scheme, most men leaving after more than 10 years' employment could be traced. For those known to have died, the date of death and the cause of death as listed on the death certificate were obtained. If a man had left the organization and could not be traced we asked for the last known address and the National Health Service number if known.

To simplify the form and for subsequent analysis, the hours of work for each job were coded into one of seven alternatives: regular day work, three shift rotas changing at weekly intervals, three shift rotas changing more frequently, alternate day and night, double days, rotating 12-hour shifts, and regular night work. The term 'shift work' is taken to include any system of working hours other than regular day work.

Allocation into groups From the completed forms each man was classified into one of four groups.

(a) Day workers Men who had completed 10 years of day work since 1946 with less than six months' previous shift work. They came under observation from the time they completed this 10 years either up to the end of 1968 or, for those few who subsequently transferred to shift work, until they had completed six months of shift work. (b) Shift workers Men who had completed 10 years on shift work since 1946, any interruption being for less than six months. They came under observation from the time they completed the 10 years until the end of 1968. Any subsequent transfer to day work did not affect their status as a 'shift worker' for this study.

(c) Ex-shift workers Men who did not qualify as shift workers but had done more than six months on shift work and subsequently transferred to day work. They came under observation when they had completed 10 years' employment and the first six months of day work following their period on shift work. They remained under observation until the end of 1968 or until they had done a further six months of shift work.

(d) Other workers There remained a few who did not fit into any of these three categories. These consisted mostly of men who had done less than 10 years' day work followed by less than 10 years' shift work. These few men were excluded from the study.

A very few men qualified for more than one of these groups, though for different intervals of time.

The completed forms for day, shift, and ex-shift workers were checked and coded prior to statistical analysis on the University of London computer. The predominant occupation during each man's qualifying period for one of the three groups was used for analysis of occupation. These jobs were coded to the three-digit 'Classification of Occupations 1966' of the General Register Office.

Tracing men until 1968 About half of the sample were still employed on 31 December 1968, and for those who had died during employment and those who had retired on a company pension, the necessary information was obtained from the company records. However, those who had left before retirement age and had withdrawn from the pension scheme could not usually be traced by the organization. There were 395 such men, and the last known address enabled us to trace 169 of them as being alive on 10 October 1968 when the Electoral Register was made up. The National Health Service Registry at Southport succeeded in tracing a further 204, 65 of whom were dead. There remained only 22 who could not be 
traced, that is $0.25 \%$ of the total sample or $5.6 \%$ of those originally untraced. They comprised nine day workers and 13 shift workers, and they were included in the analysis until the last date they were known to be alive.

Causes of death There were 1578 deaths recorded in our sample. Full details copied from death certificates were obtained for over one-third from company records and the rest were provided from the National Death Register at Somerset House. Eight could not be found because they had died outside England and Wales. Causes of death were coded to the three-digit rubric of the International Classification of Diseases (Seventh Revision, 1955) in strict accordance with the rules for selection for primary mortality tabulation.

For the 13-year period 1956 to 1968 inclusive, manyears at risk were calculated for each combination of the three intervals 1956-60, 1961-65, and 1966-68, and the five-yearly age groups $35-39,40-44$, etc. The numbers of deaths expected from the normal mortality experience of men in England and Wales were calculated by multiplying the man-years at risk in each combination of calendar period and age group by the corresponding annual mortality rates. A similar procedure was used to obtain expected deaths for different diagnostic categories but in this case the published rates for 1968 were adjusted to allow for the Registrar General's use that year of the Eighth Revision.

\section{Results}

The sample available consisted of 8767 men who fulfilled the selection criteria; 164 of these were 'other workers' whose experience could not be usefully analysed. The 10 organizations who provided the material (Table 1) covered a wide range of industry, four were in the south-east of England, four in the north-west, one in the southern region, and one in Wales. The great majority of the 4188 shift workers had worked on three-shift systems and about one-fifth had been on alternate day and night work (Table 2). There were a few men on double days and other shift systems. The very few men who had worked on more than one type of rota were allocated to the system which had occupied most time during their 10 qualifying years on shift work.

The design of this study involved men entering their period of observation at various dates from the beginning of 1956 to the end of 1968 once they qualified as day, shift or ex-shift workers. The full 13-year period could only apply to men already in employment in 1946. The number of man-years at risk for the three groups shows that most were between the ages of 45 and 69 years (Table 3). The mean duration of observation for day workers was 9.8 years, for shift workers 9.5 years, and for ex-shift workers $8 \cdot 2$ years.

\section{Mortality-all causes}

In describing the mortality experience of the sample, the comparison with national figures is put on a rigorous statistical basis by the use of significance levels based on Poisson distribution theory. Purely by chance the repeated application of such tests will result in occasional differences significant at the $5 \%$

TABLE 2

ROTAS WORKED BY SHIFT WORKERS

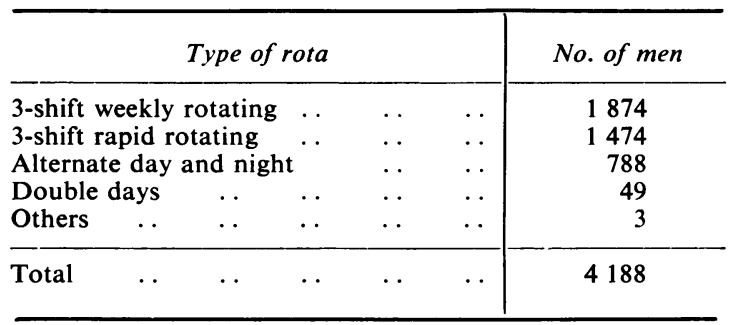

TABLE 1

Men INCluded in ANAlysis 1956-68

\begin{tabular}{|c|c|c|c|c|c|c|c|c|c|c|c|}
\hline \multirow{2}{*}{ Factory } & \multirow{2}{*}{\multicolumn{7}{|c|}{ Standard industrial classification }} & \multicolumn{4}{|c|}{ No. of men } \\
\hline & & & & & & & & Day & Shift & Ex-shift & Other \\
\hline $\begin{array}{r}1 \\
2 \\
3 \\
4 \\
5 \\
6 \\
7 \\
8 \\
9 \\
10\end{array}$ & $\begin{array}{l}\text { Bricks, pottery, etc. } \\
\text { Coal and petroleum } \\
\text { Bricks, pottery, etc. } \\
\text { Metal goods . } \\
\text { Food, drink, etc. } \\
\text { Coal and petroleum } \\
\text { Coal and petroleum } \\
\text { Vehicle manufacture } \\
\text { Metal manufacture } \\
\text { Gas, electricity, etc. }\end{array}$ & $\begin{array}{l}\cdots \\
\cdots \\
\cdots \\
\cdots \\
\cdots \\
\cdots \\
\cdots \\
\cdots \\
\cdots\end{array}$ & $\begin{array}{l}\cdots \\
\cdots \\
\cdots \\
\cdots \\
\cdots \\
\cdots \\
\cdots \\
\cdots \\
\cdots\end{array}$ & $\begin{array}{l}\cdots \\
\cdots \\
\cdots \\
\cdots \\
\cdots \\
\cdots \\
\cdots \\
\cdots \\
\cdots\end{array}$ & $\begin{array}{l}\cdots \\
\cdots \\
\cdots \\
\cdots \\
\cdots \\
\cdots \\
\cdots \\
\cdots\end{array}$ & $\begin{array}{l}\cdots \\
\cdots \\
\cdots \\
\cdots \\
\cdots \\
\cdots \\
\cdots \\
\cdots \\
\cdots \\
\cdots\end{array}$ & $\begin{array}{l}\cdots \\
\cdots \\
\cdots \\
\cdots \\
\cdots \\
\cdots \\
\cdots \\
\cdots \\
\cdots \\
\cdots\end{array}$ & $\begin{array}{r}949 \\
825 \\
251 \\
462 \\
487 \\
313 \\
208 \\
66 \\
121 \\
178\end{array}$ & $\begin{array}{r}570 \\
587 \\
881 \\
585 \\
295 \\
344 \\
224 \\
357 \\
249 \\
96\end{array}$ & $\begin{array}{r}117 \\
111 \\
53 \\
48 \\
121 \\
14 \\
31 \\
16 \\
19 \\
25\end{array}$ & $\begin{array}{r}13 \\
60 \\
39 \\
15 \\
17 \\
6 \\
6 \\
1 \\
1 \\
6\end{array}$ \\
\hline 10 & All factories & . & $\cdots$ & $\cdots$ & . & . & . & 3860 & 4188 & 555 & 164 \\
\hline
\end{tabular}


TABLE 3

Man-years of Observation by Age Group 1956-68

\begin{tabular}{c|r|r|r}
\hline Age group & \multicolumn{1}{|c|}{ Day } & \multicolumn{1}{|c|}{ Shift } & Ex-shift \\
\hline $35-$ & 464.9 & 426.4 & 66.1 \\
$40-$ & 2613.9 & 2811.6 & 311.5 \\
$45-$ & 5888.8 & 7122.7 & 695.9 \\
$50-$ & $8000 \cdot 1$ & 9046.1 & $757 \cdot 1$ \\
$55-$ & 8054.4 & 8437.5 & 928.5 \\
$60-$ & 6911.0 & 6747.6 & 914.5 \\
$65-$ & 4184.5 & 3736.7 & $599 \cdot 1$ \\
$70-$ & 1616.4 & 1117.6 & 245.0 \\
$75-$ & 226.9 & 134.7 & 44.3 \\
$80-$ & 1.9 & 0.1 & 0.7 \\
\hline All ages & 37962.8 & 39581.0 & 4562.7 \\
\hline
\end{tabular}

level. This should be borne in mind when interpreting the results presented here.

There were 1578 deaths among the men in the sample, a total very close to the 1568.7 expected from the national rates. Of the three main groups, the day workers had slightly fewer deaths than expected, but shift and ex-shift workers had slightly more (Table 4). Within 10-year age groups, however, the differences were not consistent in direction. Thus, although there were fewer deaths among day workers aged 45-54 years than expected $(P<0.05)$, and the observed ratio of shift to day deaths was also significantly greater than that expected, the situation was reversed in the 55-64 age group. For the group of ex-shift workers the population was relatively small and thus the observed slight excess of deaths, though consistent between the ages of 45 and 74, did not achieve significance at the $5 \%$ level. These results, therefore, do not show a significant overall excess mortality among shift workers nor are the differences consistent in direction in all the age groups studied.

TABLE 4

Day, ShIFT, AND Ex-SHIFT Workers Deaths Observed and EXPECTEd from All Causes

\begin{tabular}{|c|c|c|c|c|c|c|}
\hline \multirow{2}{*}{ Age group } & \multicolumn{2}{|c|}{ Day } & \multicolumn{2}{|c|}{ Sinift } & \multicolumn{2}{|c|}{ Ex-shift } \\
\hline & Obs. & Exp. & Obs. & Exp. & Obs. & Exp. \\
\hline $\begin{array}{l}35-44 \\
45-54 \\
55-64 \\
65-74 \\
75-\end{array}$ & $\begin{array}{c}9 \\
83^{1} \\
348 \\
271 \\
25\end{array}$ & $\begin{array}{r}8.8 \\
105.9 \\
325.8 \\
292.5 \\
23.3\end{array}$ & $\begin{array}{r}9 \\
142 \\
302 \\
257 \\
12\end{array}$ & $\begin{array}{r}9 \cdot 3 \\
121 \cdot 9 \\
327 \cdot 2 \\
239 \cdot 2 \\
13 \cdot 7\end{array}$ & $\begin{array}{r}0 \\
13 \\
50 \\
55 \\
2\end{array}$ & $\begin{array}{r}1 \cdot 1 \\
11 \cdot 6 \\
40 \cdot 8 \\
42 \cdot 8 \\
4 \cdot 6\end{array}$ \\
\hline All ages & 736 & $756 \cdot 4$ & 722 & $711 \cdot 4$ & 120 & $100 \cdot 9$ \\
\hline
\end{tabular}

${ }^{1}$ Fewer deaths than expected $(\mathrm{P}<0.05)$
A similar comparison was made between observed and expected deaths for men who had worked the three main types of shift rota, rapid and weekly changing three-shift, and alternate day and night work (Table 5). Here again the overall differences were not significant. In only one age group (45-54 years) in men on rapid rotating shift was the observed number significantly above that expected $(P<0.05)$. In the weekly changing three-shift system there were slightly fewer deaths than expected.

Main causes of death As a normal overall pattern of mortality might conceal an abnormal distribution of deaths by cause, we compared observed with expected deaths for a number of diagnostic categories (Table 6).

(a) All neoplasms (ICD 140-239) There were more deaths observed than expected in all three groups of men, but the difference in shift workers was the only one to reach a significant level $(P<0.05)$. Similar trends were found within this broad group for both cancer of the stomach (ICD 151) and for cancer of the bronchus and lung (ICD 162 and 163), but the differences failed to reach significant levels. No excess was found in shift workers for cancer of the bladder or for leukaemia.

In 7 out of the 10 organizations there were more neoplastic deaths among shift workers than expected though in only two did the difference achieve the $5 \%$ level of significance, and in both of these there was a significant excess of deaths from cancer of the stomach. Since there was also a slight excess of neoplastic deaths among all day workers (found in four of the organizations), the ratio of shift and day neoplastic deaths was not significantly different from the expected ratio.

(b) All cardiovascular diseases (ICD 400-468) Deaths from this large group of diseases were fewer than expected among day workers and more among shift and ex-shift workers but these differences were not

TABLE 5

SHIFT WORK ROTAS

Deaths Observed and Expected from All Causes

\begin{tabular}{|c|c|c|c|c|c|c|}
\hline \multirow{2}{*}{ Age group } & \multicolumn{2}{|c|}{$\begin{array}{c}\text { Alt. day and } \\
\text { night }\end{array}$} & \multicolumn{2}{|c|}{ 3-shift rapid } & \multicolumn{2}{|c|}{ 3-shift weekly } \\
\hline & Obs. & Exp. & Obs. & Exp. & Obs. & Exp. \\
\hline $35-44$ & 1 & $1 \cdot 5$ & 5 & 3.8 & 3 & $4 \cdot 1$ \\
\hline $45-54$ & 27 & 18.9 & $60^{1}$ & $42 \cdot 4$ & 54 & $59 \cdot 3$ \\
\hline $55-64$ & 78 & $74 \cdot 6$ & 112 & $124 \cdot 6$ & 105 & $124 \cdot 1$ \\
\hline $65-74$ & 66 & $65 \cdot 1$ & 122 & $106 \cdot 6$ & 67 & $64 \cdot 7$ \\
\hline 75 & 4 & $3 \cdot 0$ & 5 & $7 \cdot 6$ & 3 & $2 \cdot 9$ \\
\hline ages & 176 & $163 \cdot 1$ & 304 & $285 \cdot 0$ & 232 & $255 \cdot 1$ \\
\hline
\end{tabular}

${ }^{1}$ More shift deaths than expected $(P<0.05)$ 
TABLE 6

Main Causes of Death in Day, Shift, and Ex-shift Men 1956-68, Observed and Expected Numbers

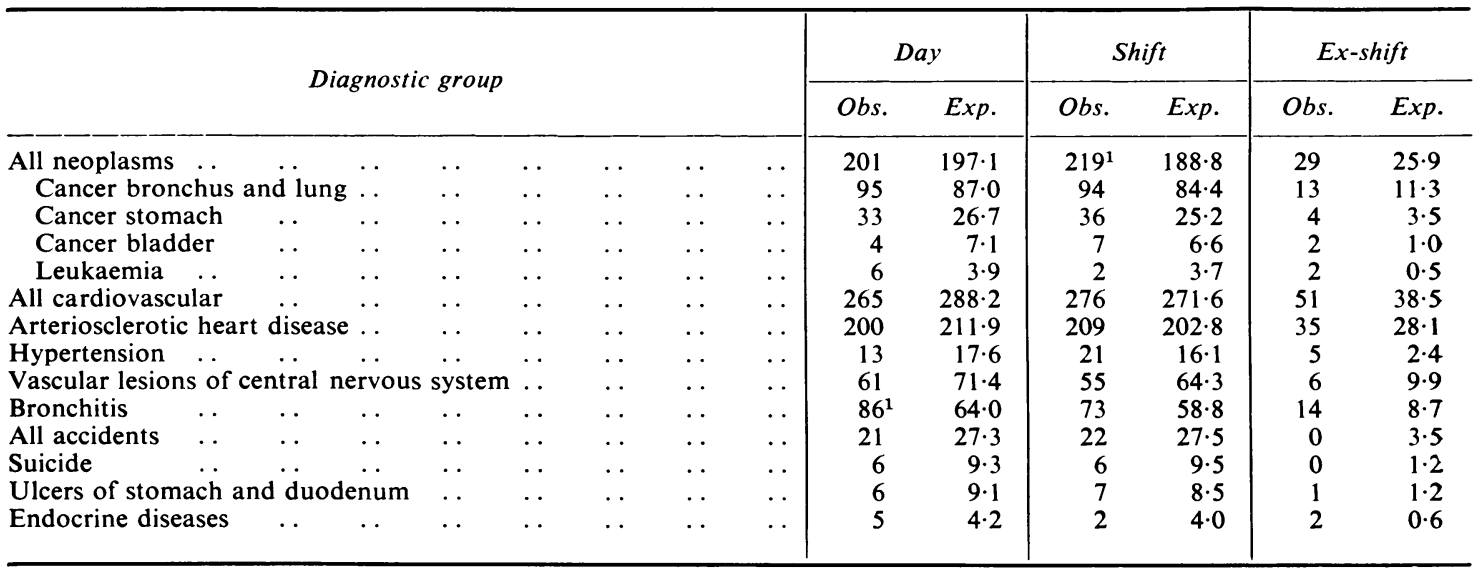

${ }^{1}$ Observed exceeds expected $(\mathrm{P}<0.05)$

For ICD rubric numbers see text

significant. Similar trends were found for arteriosclerotic heart disease (ICD 420) and hypertensive diseases (ICD 440-447). A related group of conditions, vascular lesions of the central nervous system (ICD 330-334), showed fewer deaths than expected in all three groups.

(c) Bronchitis (ICD 501 and 502) More deaths were recorded than expected from this condition in each of the three groups, but only among day workers was the difference significant $(P<0.05)$. There were no marked differences between day and shift workers.

(d) All accidents (ICD 800-999) Deaths from all types of accident were fewer than expected in each of the three groups, and for the whole sample combined this difference was significant at the $5 \%$ level. A similar pattern was found for suicides (ICD 970-979).

(e) Diseases of stomach and duodenum (ICD 540545) For this group also fewer deaths were observed than expected from national rates in each group of workers.

$(f)$ Endocrine diseases (ICD 250-277) As circadian rhythms are known to be exhibited in rates of hormone secretion it seemed advisable to look at this group of diseases. No significant difference was found between observed and expected deaths in any of the three groups.

Differences between age groups The methods used for calculating expected deaths made it possible to look for differences in the main causes of death in different age groups. While, with most of the more specific diagnoses, the numbers involved were too few to show significant differences, only one of the numerically more important groups, arteriosclerotic heart disease, showed a significant excess of deaths among shift workers under the age of 60 with 99 observed deaths against 79.9 expected $(P<0.05)$. A difference in this direction was found in the younger shift workers in 8 out of the 10 organizations but the excess was only significant in one of them. No significant excess was found in the younger ex-shift workers.

Another organization had significantly more deaths from hypertension than expected for shift workers under the age of 60 (5 observed against 0.4 expected, $\mathbf{P}<0.01)$.

Occupation and shift work It is well recognized that in any one factory most of the shift workers do different jobs from most of the day workers. These occupational factors could confound any differences in mortality which might be due to shift work as such.

Fortunately, one important activity, maintenance engineering, is often done by both day and shift workers. We were able to identify these men and compare their mortality. For skilled engineering craftsmen, 1105 men were on day work and 419 were shift workers, and for craftsmen's mates $\mathbf{3 5 0}$ were on day work and 155 on shift. These numbers were fairly evenly spread through the 10 organizations. There were 159 deaths recorded among day craftsmen as compared with 196.9 deaths expected and 71 deaths among shift workers against $79 \cdot 3$ expected. While for both groups the deaths were fewer than expected, the difference for the day 
workers was highly significant $(P<0.01)$. Among mates, however, there was a slight excess in both day and shift workers, 68 to 61.3 and 32 to 28.6 respectively. These trends are consistent with the known differences in mortality rates in social classes III and IV to which these men belonged. There was no evidence, however, of any shift work effect. Similarly, no significant differences between day and shift craftsmen and mates could be found for any of the diagncses.

\section{Discussion}

This investigation has shown, within the limitations imposed by the size of the sample, that there is no undue mortality among men who have completed 10 years of shift work or among those who did between six months and 10 years and then changed to day work. The nature of the sampling procedure introduced inevitable sources of bias but it seems unlikely that any of these affect shift rather than day workers. The fact that only relatively large organizations could take part and that each one had an occupational health service might affect the death rates by pre-employment selection and the continuing application of preventive and therapeutic care. However, the overall mortality of our sample was remarkably close to that expected from the experience of all men in England and Wales. In this respect our results differ from those of Duncan and Howell (1970) from a survey of deaths in Atomic Energy Authority employees between 1962 and 1968. They found substantially fewer deaths than expected from the national rates. One reason for this is that their sample included many scientific and other senior staff whereas ours was restricted to manual workers only. Higher mortality rates in semi-skilled and unskilled workers, who formed the bulk of our sample, have always been recognized. This social class difference could also explain the overall excess we observed from cancers of the lung and stomach.

The belief, still widely held by a substantial minority of shift workers, that shift work as such adversely affects health (Taylor, 1969; National Board for Prices and Incomes, 1970), has not been confirmed. However, a normal mortality rate alone is not the only way by which health can be assessed, and these results should be viewed in conjunction with evidence on morbidity. One fundamental and unavoidable source of possible bias, however, must be accepted in the interpretation of these results. For all but a few, shift work is undertaken voluntarily. Those who are unable, for whatever reason, to adapt themselves to its demands usually manage to find a job on day work. In some cases these men are taken off shift work on 'medical grounds', but in most the change is achieved by personal request for a transfer or by the more drastic step of resignation from the organization. The size of the group in the working population who fail to adjust to shift work is usually estimated as being in the order of $10-20 \%$ (Mott, Mann, McLoughlin, and Warwick, 1965; Bruusgaard, 1969) but accurate measurement of their number is not possible. There are also those who would never attempt shift work at all and these, too, cannot be quantified.

In studying shift workers with 10 years or more experience, we are looking at a 'survivor population' (Reid, 1957) and, moreover, one that is largely selfselected in the first place. Our ex-shift group was identified to provide some measure of those who did not survive the 10 years and these, too, did not show any significant excess in mortality. Only by a very large-scale prospective study could those who briefly try shift work or those who refuse to do it at all be studied, but there seem to be no grounds for setting up what would need to be a lengthy and difficult exercise.

An additional complication is the fundamental difference in occupations between most shift workers and day workers. In traditional shift-working industries, where continuous operation is an essential part of the technology, the shift workers tend to be plant operators and thus their occupational hazards are different from those of their maintenance colleagues on day work. It was, therefore, fortunate that we were able to identify the engineering craftsmen and their mates, and their mortality experience supported the finding that shift work did not appear to influence their expectation of life.

Only two diagnostic groups showed a significant excess of mortality among shift workers, and even these were not consistent in all 10 organizations. Moreover, by chance alone one would expect at least 2 out of the 42 comparisons set out in Table 6 to differ at the $5 \%$ level of significance. Thus the excess of deaths from tumours in shift workers and from bronchitis in day workers needs to be interpreted with caution. The high rate of fatal arteriosclerotic heart disease in younger shift workers can mostly be attributed to a substantial excess in one of the 10 organizations where it seems possible that occupational or other factors may be operating and this will require further investigation. The high death rate from hypertension in another organization again suggests a local factor and there is no evidence to suggest that it has anything to do with shift work as such.

The presentation of what are largely negative findings can be justified in view of the expressed fears among some shift workers and their representatives that their expectation of life might be affected by such 'unnatural' routines, and also from the known disturbances that have been observed in circadian rhythms. The evidence we have obtained 
frum these 10 organizations leads to the conclusion that shift work appears to have no adverse effect upon mortality.

We should like to record our gratitude to the 10 organizations which assisted us, and particular thanks are due to their medical and personnel departments for undertaking so much tedious work. We also thank Mrs. D. Bennett and other members of the staff of this Institute for their assistance. Finally, we gratefully acknowledge the advice on both methods and analysis of Professor A. M. Case and Dr. A. E. Adelstein.

\section{References}

Bruusgaard, A. (1969). Shift work as an occupational health problem. In Proceedings of an International Symposium on Night and Shift Work. Studia Laboris et Salutis, No. 4, Stockholm.

Case, R. A. M., and Lea, A. J. (1955). Mustard gas poisoning, chronic bronchitis, and lung cancer. Brit. J. prev. soc. Med , 9, 62-72.

Conroy, R. T. W. L., and Mills, J. N. (1970). Human Circadian Rhythms. Churchill, London.

Doll, R., Morgan, L. G., and Speizer, F. E. (1970). Cancers of the lung and nasal sinuses in nickel workers. Brit. $J$ Cancer, 24, 623-632.

Duncan, K. P., and Howell, R. W. (1970). Health of workers in the United Kingdom Atomic Energy Authority. Hlth Phys., 19, 285-291.

Mott, P. E., Mann, F. C., McLoughlin, Q., and Warwick, D. P. (1965). Shift Work. The Social, Psychological and Physical Consequences. University of Michigan Press, Ann Arbor.

National Board for Prices and Incomes (1970). Report No. 161. Hours of Work, Overtime and Shiftworking. Cmnd. 4554. H.M.S.O., London.

Reid, D. D. (1957). Absenteeism in industry (b). Records and research in occupational medicine. Roy. Soc. Hlth $J ., 77,675-680$.

Sergean, R. (1971). Managing Shiftwork. Gower Press, Industrial Society, London.

Taylor, P. J. (1969). The problems of shiftwork. J. roy. Coll. Phycns Lond., 3, 370-384.

Thiis-Evensen, E. (1949). 'Skiftarbeid og Helse'. Norsk Hydro, Oslo.

Tiller, J. R., Schilling, R. S. F., and Morris, J. N. (1968). Occupational toxic factor in mortality from coronary heart disease. Brit. med. J., 4, 407-411.

Received for publication June 29, 1971. 